\title{
Teachers' Attitudes and Perceptions: Association of Teachers' Attitudes toward Traditional and Modern Teaching Methodology According to RWCT as Well as Teachers' Perceptions for Teaching as a Profession
}

\author{
Xhevahire Karanezi ${ }^{1}$, Edmond Rapti ${ }^{2}$ \\ ${ }^{1}$ Independent, Pristina, Kosovo \\ ${ }^{2}$ University of Tirana, Tirana, Albania \\ Email: xhevahirekaranezi@gmail.com, edi rapti@yahoo.com \\ Received 3 March 2015; accepted 14 April 2015; published 17 April 2015 \\ Copyright (C) 2015 by authors and Scientific Research Publishing Inc. \\ This work is licensed under the Creative Commons Attribution International License (CC BY). \\ http://creativecommons.org/licenses/by/4.0/

(c) (i) Open Access

\begin{abstract}
Teaching methodologies that are chosen to be used by teachers in their daily work are highly impacted by their attitudes and perceptions. According to Schoenfeld (1992) attitudes and perceptions influence teachers not only how, but what, he or she teaches. The data collection for this study was conducted using quantitative and qualitative method. There were 473 school teachers throughout Kosovo that participated in this study. Questionnaires were used to collect all quantitative data, which were compiled and adjusted in accordance with the study objectives. Focus groups discussions were conducted for the purpose of collecting the qualitative data. The data showed significant negative association between teachers' attitudes toward traditional teaching methodologies and modern teaching methodologies according to RWCT $(r=-0.446$, sig $=0.000)$. The data also showed that there was a significant negative association between attitudes toward traditional teaching methodology and teachers' perceptions for teaching as a profession $(r=-0.092, \operatorname{sig}=$ 0.046). The quantitative results were in the same line with the qualitative findings of the study.
\end{abstract}

\section{Keywords}

Attitudes, Perceptions, Traditional Methodology, Modern Methodology, RWCT 


\section{Introduction}

Traditional teaching methodologies with teacher in the center were not anymore applicable, considering the new changes and daily challenges that the society was facing. As a result, new teaching methodologies, with the student in the center, are being implemented all over the world, by continuously promoting critical thinking. According to Richards (2008) traditional methodology was explained as learning that was very much seen as under teacher's control. In this regard the traditional classrooms were seen like ceremonial places where students sat in rows like spectators, while the teacher sat in front of them as a mayor or a priest (Crawford et al., 2005). Unlike traditional methodology, the modern teaching methodology is much more student-centered. Scrivener (2005) explains that in modern methodology the main role of the teacher is to help students in the process of learning by encouraging, involving and helping them to try out and explore.

Critical Thinking about Reading and Writing (RWCT) is an initiative of the Open Society Institute (OSI) and the International Reading Association (IRA) with special focus on teaching methods. As a professional development program for teachers, RWCT program provides specific strategies for interactive teaching methods that help teachers to prepare their students to become active citizens in an open society (American Institute for Research, 2001). It should be noted that studies show that teacher reported that they benefit a lot in terms of their personal career by attending RWCT program (Covac \& Cretu, 2010). Also, it is important to note that RWCT techniques resulted with strong impact on the relationship and cooperation between teachers and students, teachers and their peers as well as teachers and the rest of the school community (Musai \& Wile, 2004). Therefore, as a modern teaching methodology, RWCT is seen more than an attempt to replace traditional teaching methodology with innovative teaching techniques (Wile \& Ulqini, 2003). In Kosovo, RWCT program started for the first time in October, 2000 and was implemented by Kosovo Education Center (Pupovci \& Taylor, 2003). In the last decade, RWCT in Kosovo was one of the largest educational development programs, with high popularity, which reached out almost one fourth of all teachers in the country (Rado, 2013).

\section{Literature Review}

Teaching methodologies that are chosen to be used by teachers in their daily work are highly impacted by their attitudes and perceptions. According to Schoenfeld (1992) attitudes and perceptions influence teachers not only how, but what, he or she teaches. As such, teachers' attitudes and perceptions impact their teaching style, selected resources, as well as classroom establishment. It is of great importance to be noted that oftentimes teachers' attitudes and perceptions are passed on to the students through their teaching (Barnyak \& Paquette, 2010). Therefore, attitudes and perceptions of teachers can impact not only students' motivation to learn, but also impact the entire environment in which students learn (OECD, 2009).

Considering the importance of teachers' attitudes and perceptions, its impact to students and learning process in general, numerous studies have been focused on studying them (National Reading Panel, 2000; Kher \& Burrill, 2005; Webb et al., 2006). The National Reading Panel committee (2000) decided to research about teachers' education focusing on improving teachers' attitudes. The Panel found that teachers' attitudes (either in-service or pre-service teachers) changed when interventions occurred. Therefore, pre-service teachers learned teaching methods by their own attitudes in regard to teaching and education, while in-service teachers may have improved or changed their attitudes as a result of the intervention, in this case training programs. Furthermore, according to American Institute for Research (2001) the professional development experiences can affect teacher's attitudes about teaching and learning. More specifically, changing teaching methodology requires first change in teachers' believes on how students learn and what effective teaching strategies mean to teachers (Webb et al., 2006; Kher \& Burrill, 2005). Findings from these studies are of great importance, as they provide enough evidence that changing teachers' attitudes is the right way to change their teaching methodology and style. Hence, in order to change practices, attitudes must change first (National Reading Panel, 2000).

As for the RWCT program, studies have found that participation in such program has resulted with positive perceptions of teachers in regard to the impact of the program that has shown in their teaching practice (Pupovci \& Taylor, 2003; Musai \& Wile, 2004; Rado, 2013). Moreover, it was found that RWCT program not only had a major impact on teaching practices and student performance, but also in teacher's attitudes and learners (American Institute for Research, 2001). However, as stated in the report of National Reading Panel (2000) although teaching practices may change as a result of education or trainings, it is concerning that it is not clear for how long these changes are sustainable. There is a tendency of the teachers to use new methods only during the time 
that are being observed or monitored. As Rado (2013) explains, participation in a 120 hours training, which RWCT program provides, rarely causes deep cognitive and attitudinal changes (Rado, 2013). On the other hand, the literature emprise that when teachers are unfamiliar with the research behind a method or program in use, attitudes tend to be more negative (Demant \& Yates, 2003).

From the perspective of education policy, it is very important to look at the impact of background factors such as type of training, professional development, subject taught employment status, etc. on teachers' attitudes and perceptions. Regardless of that fact, teachers have always been expected to devote themselves to the profession they are doing. According to LaCour (2005) if we ask veteran teachers what their job is like, they will answer: difficult, wonderful, exhausting, fun, stressful, enlightening and rewarding. Then, when we ask them, if they would choose the same career if they could live their lives over, the answer is usually "Yes" (LaCour, 2005). However, the content of courses in the teacher education programs, or the content of the training programs for teachers have a significant role in developing positive attitudes toward teaching as a profession (Maliki, 2013).

\section{Methodology}

The data collection for this study was conducted using quantitative and qualitative method. There were 473 school teachers throughout Kosovo that participated in this study. Questionnaires were used to collect all quantitative data, which were compiled and adjusted in accordance with the study objectives. Focus groups discussions were conducted for the purpose of collecting the qualitative data. According to Krueger (1998) focus groups discussions helps to explore and understand more the specific issues, going into a deeper level then quantitative methods. Also, it helps the researchers to understand much better and in a deeper level specifically participants' perception, thoughts and feelings in regard to the specific issues (Krueger \& Casery, 2000). Hence, for the purpose of this study, in order to obtain in depth information and to better understand teachers' perceptions and attitudes toward traditional and modern teaching methodologies, 4 focus groups discussions were conducted with school teachers' of primary and lower secondary school throughout Kosovo.

\subsection{Participants}

Primary and lower secondary school teachers throughout Kosovo participated in this study. The study was conducted in 23 primary and lower secondary schools in Kosovo, and data were collected from 6 different regions throughout Kosovo with respect to urban and rural stratification. All questionnaires were administrated in the respective school premises. Focus groups discussions were also conducted in the school premises, and were comprised of 6 to 8 participants. A consent form was given to all focus groups participants to claim their willingness to participate and freely discuss in the focus groups discussion.

\subsection{Instruments}

For the quantitative data collection, a specific questionnaire was used, which was compiled in accordance with the study objectives. Some of the questions were adapted by the questionnaire, which was used by Pupovci and Taylor (2003) for one of the studies conducted with Kosovar teachers previously. This questionnaire was originally constructed by American Institute for Research which was then used by Pupovci and Taylor (2003). For further testing applicability and comprehensives of the questionnaire, a pilot study was conducted prior to the main data collection. The pilot was conducted with teachers from two primary schools which were not selected for the main data collection. During the pilot study, teachers were asked to fill in a questionnaire and after that were invited for an open discussion and give their feedback about the questions and the questionnaire in general. The pilot resulted with the modification of few questions and there were no questions recommended to be added or removed. All teachers' recommendations from the pilot study were integrated in the final version of the questionnaire which was used for the main data collection.

\subsection{Procedure of Data Collection}

All questionnaires used for quantitative data collection were administrated in the school premises. The questionnaires were administrated in different rounds in small groups of teachers, in order to ensure privacy and enough space for each participant. During the entire process of the data collection, teachers were informed and encouraged to ask for anything that might have been not clear to them. The focus groups discussions were also 
conducted in school premises with 6 to 8 participants and were conducted after teachers' official working hours. The focus groups discussions were conducted in a separate physical space where nobody apart the research team had access. Before starting with the focus groups discussion, the participants of each focus group were first informed about the flow of the discussion, their right to withdraw and were strongly encouraged to actively participate and contribute to the discussion. The participants were asked for permission in order for the focus groups discussion to be recorded.

\section{Results}

The data were analyzed based on three subscales (teachers' attitudes toward traditional teaching methodology, attitudes toward modern teaching methodology such as RWCT, and perceptions for teaching as a profession) which were calculated from the quantitative data. Correlation analysis were conducted in order to observe the association of attitudes toward traditional teaching methodology and attitudes toward modern teaching methodology according to RWCT, as well as teachers' perceptions for teaching as a profession.

The data presented in Table 1 show a clear association between teachers' attitudes toward traditional teaching methodology and attitudes toward modern teaching methodology according to RWCT, as well as teachers' perceptions for teaching as a profession.

The data show that there is a significant negative association between attitudes toward traditional teaching methodology and teachers' attitudes toward modern teaching methodology $(r=-0.446$, sig $=0.000)$. Also, the data show that there is a significant negative association between attitudes toward traditional teaching methodology and teachers' perceptions for teaching as a profession $(r=-0.092$, sig $=0.046)$. Furthermore, a significant positive association between teachers' attitudes toward modern teaching methodology and their perceptions for teaching as a profession was found $(r=0.331$, sig $=0.000)$.

\section{Findings from Focus Groups Discussions}

Based on the qualitative data, it can also be noted that there is a difference between teachers' attitudes toward traditional teaching methodology and modern teaching methodology according to RWCT. The data showed that most of the teachers who are applying traditional teaching methodology and did not attend any of the RWCT trainings did not show very positive attitudes toward modern teaching methodology, especially those teachers who did not have enough information for modern teaching methodology. Based on the focus groups discussions, teachers who are applying traditional teaching methodology felt comfortable on using this method and did not share a positive opinion for modern teaching methodologies such as RWCT, which was usually associated as such methodology which brings noise in the classrooms, students can easily hide themselves after students who are more hard-workers, etc.

Participant (1) I always apply traditional teaching methods, and actually I do not see anything wrong on that. I do not think that modern teaching methodology would give something more to the students.

Participant (2) I personally don't think that these modern teaching methodologies are suitable since when these techniques are applied in the classroom, they bring a lot of noisy and students are not able to listen anything.

Table 1. Association of teachers' attitudes toward traditional teaching methodology and attitudes toward modern teaching methodology as well as teachers' perceptions for teaching as a profession.

\begin{tabular}{|c|c|c|c|c|}
\hline & & $\begin{array}{c}\text { Traditional } \\
\text { teaching methodology }\end{array}$ & $\begin{array}{l}\text { Modern teaching } \\
\text { methodology as is RWCT }\end{array}$ & $\begin{array}{l}\text { Teachers’ } \\
\text { perceptions }\end{array}$ \\
\hline \multirow{2}{*}{$\begin{array}{l}\text { Traditional teaching } \\
\text { methodology }\end{array}$} & Pearson Correlation & 1 & $-0.446^{* *}$ & $-0.092^{*}$ \\
\hline & Sig. (2-tailed) & & 0.000 & 0.046 \\
\hline \multirow{2}{*}{$\begin{array}{l}\text { Modern teaching } \\
\text { methodology as is RWCT }\end{array}$} & Pearson Correlation & $-0.446^{* *}$ & 1 & $0.331^{* *}$ \\
\hline & Sig. (2-tailed) & 0.000 & & 0.000 \\
\hline \multirow{2}{*}{$\begin{array}{l}\text { Teachers' } \\
\text { perceptions }\end{array}$} & Pearson Correlation & $-0.092^{*}$ & $0.331^{* *}$ & 1 \\
\hline & Sig. (2-tailed) & 0.046 & 0.000 & \\
\hline
\end{tabular}


In terms of teachers who reported that they apply RWCT techniques in their daily work and did attend RWCT trainings, traditional teaching methodology was seen as a dictatorial teaching technique which was mostly associated with the teacher in the center and students as observers. Traditional teaching methodology was also associated with no freedom for expressing student's opinions, fear and less motivated students.

Participant (1) Traditional teaching methodology is very dictatorial, the teacher is in the center and students are not allowed to give their opinions. Students are those who are always afraid of teacher, as he is the one who asks for discipline and order.

Participant (2) I think that teaching methodology has an important role on student's motivation for school. Traditional teaching methodology is less motivated for children, is boring for both teacher and student, is more or less a routine; there are no attractive activities for students that a teacher can apply.

Participant (3) Modern teaching methodology such as RWCT, is just perfect for both students and teachers. It helps students to be more involved and independent, but above all, it is important that this methodology has changed my approach to students, especially in terms of cooperation.

In terms of teacher's perceptions toward teaching as a profession, there were no clear differentials, and in general all teachers presented with high positive perceptions toward teaching as a profession.

Participant (1) Even if I would have to choose for my profession again, I would choose to be a teacher, is just the most human profession that exists.

Participant (2) Being accompanied by innocent and sincere children makes me happy every day. I love using all RWCT techniques with my students; I love to hear their wonderful innovative ideas, therefore, I would never change my profession as a teacher.

It is also important to be noted that numerous teachers who are not currently applying modern teaching techniques and did not have the chance to attend any of the RWCT trainings, expressed their willingness and readiness to gain more knowledge on the RWCT techniques and did not reported high positive attitudes toward traditional teaching methodologies.

\section{Discussion}

The aim of the study was to investigate the association of teachers' attitudes toward traditional teaching methodology and teachers' attitudes toward modern teaching methodology according to RWCT, as well as their perceptions for teaching as a profession. In order to have a better understanding in regard to teachers' attitudes and perceptions, qualitative data were collected and analyze.

The quantitative data showed that there is a significant association between teachers' attitudes toward traditional teaching methodology and their attitudes toward modern teaching methodology such is RWCT. Respectively, the data showed that teachers with positive attitudes toward traditional teaching methodology have negative attitudes toward modern teaching methodology. Furthermore, the qualitative data also showed that most of the teachers who are actually applying traditional teaching methodology on their daily work are satisfy with these techniques and do not have very positive attitudes toward modern teaching methodologies such as RWCT. The qualitative findings showed that teachers who are applying traditional teaching methodology and did not attend any of the RWCT trainings feel comfortable with their teaching techniques and usually modern teaching methodologies for them are associated with teaching techniques that brings noise in the classroom, which shows that these teachers do not feel comfortable with having noise in the classroom and prefer more absolute silent during their daily work. This clearly indicate that teachers who apply traditional teaching methodology are not very open to have discussion with students, neither students with each other, and still not aware that noise does not necessarily indicate that students are not learning, listening or working, but just the opposite, an environment when students freely discuss and exchange their ideas. Findings from this study are in line with previous findings from the other studies which showed that there is a change in teacher's attitudes when interventions occurred (National Reading Panel, 2000). In contrary, most of the teachers who showed positive attitudes for modern teaching methodologies and attended RWCT trainings showed more negative attitudes toward traditional teaching methods. Traditional teaching methods were mostly described as dictatorial, disciplining, order and fear from the teachers. This show that teachers who are applying modern teaching methodology promote more students critical thinking and make students more actively involved in the learning process. Furthermore, modern teaching methodology was explained as more motivational for both students and teachers. It is important to be noted, that teachers who apply modern teaching methodology describe traditional teaching methodology as 
dictatorial, and methodology that does not promote open discussion, which is more or less what teachers who apply traditional teaching methodology declare, that noise is not welcomed in their daily work with students. This can also be explained that trainings can affect teacher's practices and attitudes about teaching and learning (American Institute for Research, 2001).

In terms of teachers' perceptions for teaching as a profession, quantitative data showed significant positive association between teachers' attitudes toward modern teaching methodology and teachers' positive perceptions for teaching as a profession. On the other hand, the data resulted with significant negative association between teachers' attitudes toward traditional teaching methodology and their perceptions for teaching as a profession. Respectively, teachers who showed positive attitudes toward traditional teaching methodology showed negative perceptions for teaching as a profession. Nevertheless, findings from focus groups discussions showed that in general all teachers reported highly positive perceptions for teaching as a profession. It should be noted that, even in the focus groups discussion, modern teaching methodology was described as very motivated for both students and teachers, which make the quantitative results more powerful when considering that teachers who apply modern teaching methodology presents with more positive perceptions for teaching as a profession compare to those who apply traditional teaching methodology.

\section{Conclusion}

Based on the data presented in this study it can be concluded that there is a significant negative association between teachers' attitudes toward traditional teaching methodology and their attitudes toward modern teaching methodology such as RWCT. Respectively, teachers who have positive attitudes toward traditional teaching methodology have negative attitudes toward modern teaching methodology such as RWCT. The data also showed that there was a significant positive association between teachers' attitudes toward modern teaching methodology such as RWCT, and teachers' perceptions for teaching as a profession, as well as significantly negative association between teachers' attitudes toward traditional teaching methodology and their perceptions for teaching as a profession. Based on the findings from focus groups discussions, in general, most of the teachers showed highly positive perceptions for teaching as profession. Furthermore, based on the findings from focus groups discussions it was also found that most of the teachers who have positive attitudes toward traditional teaching methodology and did not attend any of RWCT trainings associated modern teaching techniques with noise, ability of some students to hide after students who are more hard-workers, which explains teachers preferences on working in an absolute silent environment, and preferences to discipline and order. On the other hand, teachers who reported positive attitudes toward modern teaching methodology and did attend RWCT trainings, associated traditional teaching methodology as dictatorial, discipline, order and no actively involved of students, indicating their preference for reinforcing a more cooperative approach with their students and promote students critical thinking.

\section{References}

American Institute for Research (2001). The 2000-2001 Reading and Writing for Critical Thinking Project Impact and Institutionalization Study. New York: OSI.

Barnyak, N. C., \& Paquette, K. (2010). An Investigation of Elementary Preservice Teachers Reading Instruction Beliefs. Reading Improvement. Farmington Hills, MI: Gale Group.

Covac, M., \& Cretu, N. (2010). Critical Thinking Program Review. OSI.

Crawford, A., Saul, W., Mathews, S., \& Makinster, J. (2005). Teaching and Learning Strategies for the Thinking Classrooms. New York: The International Debate Education Association.

Demant, M. S., \& Yates, G. C. (2003). Primary Teachers’ Attitudes toward Direct Instruction Construct. Educational Psychology, 23, 483-489. http://dx.doi.org/10.1080/0144341032000123741

Kher, N., \& Burrill, G. (2005). PD3-PCMI and Districts Partner to Design Professional Development: Implementation Challenges and Evaluation Design. National Science Foundation's Mathematics and Science Partnership Evaluation Summit, Minneapolis, MN.

Krueger, R. A. (1998). Moderating Focus Groups. Thousand Oaks, CA: Sage Publications.

Krueger, R., \& Casey, M. (2000). Focus Groups. A Practical Guide for Applied Research (3rd ed.). Thousand Oaks: Sage Publications.

LaCour, N. (2005). Becoming a Teacher. The Black Collegian Online. http://www.blackcollegian.com/becoming-a-teacher/ 
Maliki, A. E. (2013). Attitudes towards the Teaching Profession of Students from the Faculty of Education, Niger Delta University. International Journal of Social Science Research, 1, 11-18.

Musai, B., \& Wile, J. (2004). Lesson from Albania: Professional Development That Transforms Educators, Schools and Communities. Mediterranean Journal of Educational Studies, 9, 1-20.

National Reading Panel (2000). Teaching Children to Read: An Evidence-Based Assessment of the Scientific Research Literature on Reading and Its Implications for Reading Instruction: Reports of the Subgroups. Bethesda, MD: National Institute of Child Health and Human Development, National Institutes of Health.

OECD (2009). Teaching Practices, Teachers’ Beliefs and Attitudes. In Creating Effective Teaching and Learning Environments: First Results from Teaching and Learning International Survey (TALIS) (pp. 87-135). OECD Publishing. http://www.oecd.org/education/school/43023606.pdf http://dx.doi.org/10.1787/9789264068780-6-en

Pupovci, D., \& Taylor, A. (2003). Reading and Writing for Critical Thinking. Final Evaluation Report, Prishtinë: Kosova Education Centre.

Rado, P. (2013). The Evaluation of the Reading and Writing for Critical Thinking Program in Kosovo. Final Evaluation Report, Prishtinë: Kosova Education Center.

Richards, J. C. (2008). Communicative Language Teaching Today. New York: Cambridge University Press.

Schoenfeld, A. H. (1992). Learning to Think Mathematically: Problem Solving, Metacognition, and Sense-Making in Mathematics. In D. Grouws (Ed.), Handbook for Research on Mathematics Teaching and Learning (pp. 334-370). New York: MacMillan.

Scrivener, J. (2005). Learning Teaching. Oxford: MacMillan.

Webb, N. M., Nemer, K. M., \& Ing, M. (2006). Small-Group Reflections; Parallels between Teacher Discourse and Student Behavior in Peer-Directed Groups. Journal of the Learning Sciences, 15, 63-119. http://dx.doi.org/10.1207/s15327809jls1501_8

Wile, M. J., \& Ulqini, L. (2003). Developing Critical Thinking Skills in Eastern Europe. Proceedings of the World Bank's International Workshop on Curricula, Textbooks, and Pedagogical Practices and the Promotion of Peace and Respect for Diversity, Washington DC, 24-25 March 2003. 


\section{Appendix}

\section{Some of the Questions Used in the Questionnaire:}

1. Traditional methodology is more successful compare to modern methodology such is RWCT.

Totally disagree

Somewhat disagree

Don't know

Somewhat agree

Totally agree

2. Traditional teaching methodology is boring for students.

Totally disagree

Somewhat disagree

Don't know

Somewhat agree

Totally agree

3. If I could start my career all over again, I would not have chosen the teaching profession.

Totally disagree

Somewhat disagree

Don't know

Somewhat agree

Totally agree

4. I love my job working as a teacher.

Totally disagree

Somewhat disagree

Don't know

Somewhat agree

Totally agree

5. I have enough autonomy to decide in my own on which teaching strategies to use in my daily work.

Totally disagree

Somewhat disagree

Don't know

Somewhat agree

Totally agree

\section{Some of the Questions Used for the Focus Group Discussions:}

1. Are you familiar with RWCT or critical thinking strategies?

2. Have you ever attended RWCT training? If no, what is the reason for not attending this training?

3. Do you apply any of the RWCT methods during your daily work with students? If yes, please explain? If no, please explain?

4. Do you apply traditional methodologies in your daily work with students? If yes, are you satisfied with this methodology of teaching?

5. If you could start your career all over again, would you still choose to be in the teaching profession? 